\title{
System Stability of a 3T-MRI During Continuous EPI Scan
}

Original

\author{
Yasuhiro Shimada, Takanori Kochiyama, ${ }^{1)}$ Ichiro Fujimoto, ${ }^{1}$ \\ Shinobu Masaki, ${ }^{1)}$ and Kenya Murase ${ }^{2)}$
}

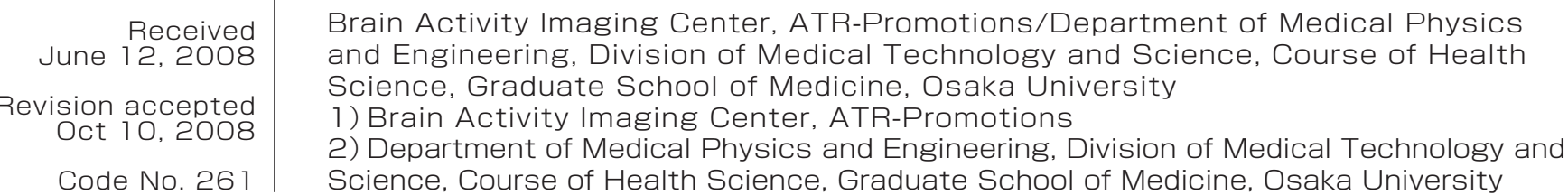

Code $\mathrm{No} \cdot 261$

\section{Introduction}

The high field magnetic resonance imaging (MRI) system has become widespread in the clinical field due to its intrinsically higher signal-to-noise ratio (SNR), driven by recent improvements in the RF pulse ${ }^{1,2)}$ and receiver coil system ${ }^{3-7)}$ (e.g. multi-channel phased array coil). In addition, it has also been intensively used in the non-invasive brain functional imaging community. Thus, it is important to know the general characteristics of high field MRI.

At the ATR-Brain Activity Imaging Center (ATRBAIC), functional-MRI (f-MRI) experiments using an echo planar imaging (EPI) sequence have been routinely performed, and we are especially concerned about the stability of EPI. The EPI sequence has been widely used for f-MRI. Although this sequence can detect a subtle magnetic field change resulting from activations of the local brain, it is easily affected by physiological alterations $^{8-10)}$ such as respiration, pulsation, and subject motion in addition to system instability due to a main magnetic field (B0) change ${ }^{11-15)}$ throughout data acquisition.

The experimental paradigms of f-MRI are diverse. In many cases, the EPI sequence of several minutes is repeated several times, but long duration (more than 30 min) scanning is sometimes required. ${ }^{16)}$ In such a situation, the signal stability over time series is inevitably important and, if not maintained, the results of the statistical analysis might degenerate because of large noise components.

In our previous study, ${ }^{17,18)}$ we reported large signal fluctuations in EPI time series due to B0 instability of the 1.5T MRI at ATR-BAIC and proposed some solutions, including system warm-up and/or image shift corrections (along the phase direction). The implementation of these procedures succeeded in preventing the under- and over-estimation of brain activation. Since the characteristics of an MRI system highly depend on B0 strength and even the manufacturer, ${ }^{19-23)}$ we have to

\section{Summary}

The purpose of this study is to evaluate the general stability and image properties of a 3T MRI system newly installed at the ATR-Brain Activity Imaging Center (ATR-BAIC), in addition to a conventional 1.5T system. In this study, we focused on the echo planar imaging (EPI) sequence since continuous EPI with a relatively long duration of up to $30 \mathrm{~min}$ is routinely used, and the stabilization of EPI is always a concern. The following five results were obtained: (1) Significant image shifts along the phase direction were observed in the $1.5 \mathrm{~T}$ data but not in the 3T data, although B0 shifts in both the $1.5 \mathrm{~T}$ and $3 \mathrm{~T}$ systems were the same level $(1.3 \mathrm{~Hz} / \mathrm{min})$; (2) The signal fluctuations were $1 / 2-1 / 3$ smaller in the $3 \mathrm{~T}$ system compared with the $1.5 \mathrm{~T}$ system; (3) The temporal signal-to-noise ratio (TSNR) of the 3T system was 1.7-2.0 (CP-coil) and 2.5-4.0 (12ch-coil) greater than the $1.5 \mathrm{~T}$ system; (4) We found a low frequency periodic fluctuation (cycles of approximately 30-40 sec), and an increase in noise in the latter half of the long term series, which might originate from the 3T MRI scanner; and (5) Spatial non-uniformity of TSNR and voxels with a linear-trend were observed in the $3 \mathrm{~T}$ data.

Key words: 3T-MRI, EPI, spatio-temporal stability 
Table 1 Imaging parameters

\begin{tabular}{|c|c|c|}
\hline & $1.5 \mathrm{~T}$ & 3Т \\
\hline \multicolumn{3}{|l|}{ Phantom } \\
\hline TR & $5000 \mathrm{msec}$ & $3000 \mathrm{msec}$ \\
\hline TE & $49 \mathrm{msec}$ & $30 \mathrm{msec}$ \\
\hline FA & $90^{\circ}$ & $80^{\circ}$ \\
\hline FOV & $192 \mathrm{~mm}$ & $192 \mathrm{~mm}$ \\
\hline Matrix & $64 \times 64$ & $64 \times 64$ \\
\hline Slice thickness & $4 \mathrm{~mm}$ & $4 \mathrm{~mm}$ \\
\hline Number of slice/volume & 50 (no gap, interleave) & 50 (no gap, interleave) \\
\hline BW (phase direction) & $23.15 \mathrm{~Hz} /$ pixel & $37 \mathrm{~Hz} /$ pixel \\
\hline BW (frequency direction) & $1482 \mathrm{~Hz} /$ pixel & $2368 \mathrm{~Hz} /$ pixel \\
\hline \multicolumn{3}{|l|}{ Volunteer } \\
\hline TR & $1000 \mathrm{msec}$ & $1000 \mathrm{msec}$ \\
\hline TE & $45 \mathrm{msec}$ & $30 \mathrm{msec}$ \\
\hline FA & $60^{\circ}$ & $60^{\circ}$ \\
\hline FOV & $192 \mathrm{~mm}$ & $192 \mathrm{~mm}$ \\
\hline Matrix & $64 \times 64$ & $64 \times 64$ \\
\hline Slice thickness & $3 \mathrm{~mm}$ & $5 \mathrm{~mm}$ \\
\hline Number of slice/volume & 10 (no gap, interleave) & 16 (no gap, interleave) \\
\hline BW (phase direction) & $23.15 \mathrm{~Hz} /$ pixel & $37 \mathrm{~Hz} /$ pixel \\
\hline BW (frequency direction) & $1482 \mathrm{~Hz} /$ pixel & $2368 \mathrm{~Hz} /$ pixel \\
\hline
\end{tabular}

validate the system stability of a newly installed 3T-MRI.

To achieve high-quality data acquisition, we evaluate our 3T-MRI system in terms of the spatio-temporal characteristics of the image time series, including temporal signal change, periodic fluctuation, temporal SNR (TSNR) and trend, during a long duration (30 min) EPI scan.

\section{Method}

Comparative studies were performed at different field strengths on a $1.5 \mathrm{~T}$ whole body MRI system (Gradient coils strength of $27 \mathrm{mT} / \mathrm{m}$ and a maximum slew rate of $72 \mathrm{~T} / \mathrm{m} / \mathrm{s}$ ), the Magnex ECLIPSE (ShimadzuMarconi, Kyoto, Japan) and a 3T whole body MRI system (Gradient coils strength of $45 \mathrm{mT} / \mathrm{m}$ and a maximum slew rate of $200 \mathrm{~T} / \mathrm{m} / \mathrm{s}$ ), the Magnetom Trio a Tim (Siemens, Erlangen, Germany). A spherical phantom (17 cm in diameter and doped with $1.25 \mathrm{~g}$ $\mathrm{NiSO}_{4} \times 6 \mathrm{H}_{2} \mathrm{O}$ per $1000 \mathrm{~g} \mathrm{H}_{2} \mathrm{O}$ ) provided by the MRI vendor and three healthy volunteers (one volunteer for the $1.5 \mathrm{~T}$ and two volunteers for the $3 \mathrm{~T}$ ) were scanned in a long-duration (up to $30 \mathrm{~min}$ ) 2D EPI acquisition. The room temperature had been set to $23^{\circ} \mathrm{C}$ all day. The phantom was placed in the scanner room overnight or longer before the experiment. Informed consent was obtained from every volunteer before participation in this study.

A receive-only quadrature detection (QD) head coil for $1.5 \mathrm{~T}$ and two types of head coils including a transmit/receive cross polarization $(\mathrm{CP})$ head coil and a receive-only $12 \mathrm{ch}$ head matrix coil for $3 \mathrm{~T}$ were used. The 12ch head matrix coil supports three types of imaging modes (4ch CP-mode, $8 \mathrm{ch}$ dual-mode and $12 \mathrm{ch}$ triple-mode), and we used triple-mode in this study because of higher image homogeneity and SNR in the preparatory experiment.

Since the purpose of this study is to evaluate under actual f-MRI conditions, selected imaging parameters were set to nearly maximum system load conditions. Consequently, imaging parameters were not identical between the systems depending on system limitations. Imaging parameters are summarized in Table 1.

\section{1-1 B0 change and image shift}

To investigate the effects of the change in the magnetic field with increased scanning time, we measured the central frequency and image shift. From 
April 25 to May 22, 2002, we measured the center frequency before and after system warm-up for more than 20 min on the $1.5 \mathrm{~T}$ system and calculated the centroid position (i.e. image shift) of the phantom image obtained by EPI (BW $23.15 \mathrm{~Hz} /$ pixel). From August 27 to October 24, 2007, we also measured the center frequency before and after a $30 \mathrm{~min}$ EPI with $\mathrm{BW} 37 \mathrm{~Hz} /$ pixel on the $3 \mathrm{~T}$ system three times in the phantom and once in the volunteers, and image shifts were estimated using realign functions in the SPM99 software (Welcome Department of Cognitive Neurology, London, UK) for phantom data only. The data from volunteers (dash mark " - " at 3 T data 2 on Table 2) were excluded from this analysis to avoid the confounding effects of body motion.

\section{1-2 Signal fluctuation}

To investigate signal fluctuations over time series, percent signal change ( $P S C_{i}$ in eq. 1) was evaluated. We first calculated the mean signal intensity of each slice for all volumes. To eliminate the spatially varying fluctuations due to image shifts, we used the mean value of all voxels (pixels) within a slice instead of ROI placed in the specific area. The sum of the total pixel values through the plane were divided by the number of pixels: $64 \times 64=4096$ pixels/slice, giving $S_{\text {mean }, i}$ in eq. 1 , where the suffix mean represents the slice-based mean and the number of volumes is indexed by $i$. The time series of a particular slice was then normalized by the first observation $\left(S_{\text {mean }, i}\right.$ in eq. 1$)$. The resulting time series, hence, indicated the percentage of signal fluctuation relative to the start of scanning.

$$
P S C_{i}=\left(S_{\text {mean }, i} / S_{\text {mean }, 1}\right) \times 100
$$

\section{1-3 Periodic fluctuation}

In order to evaluate the periodic fluctuation, we estimated the auto correlation function $(\mathrm{ACF})$ and cross correlation function $(\mathrm{CCF})$ at the middle slice of PSC (c.f. eq. 1). These functions are suitable for finding the periodical structures in a noisy time series. Before ACF and $\mathrm{CCF}$ were calculated, the low frequency trend was removed by 5 th order orthogonal polynomial and centered by the grand mean of time series $(R)$.

The ACF was defined as:

$$
A C F(j)=\frac{1}{N} \sum_{i=1}^{N} R(i) \cdot R(i+j) \quad j=0,1,2, \cdots, N \cdots(2)
$$

where $j$ is lag and $N$ is the total number of acquisitions. Similarly, the CCF was defined as:

$$
C C F(j)=\frac{1}{N} \sum_{i=1}^{N} R b(i) \cdot R c(i+j) \quad j=0,1,2, \cdots, N \cdots(3)
$$

where $R b$ and $R c$ are the de-trended time series from volunteers $\mathrm{B}$ and $\mathrm{C}$.

\section{1-4 Temporal Signal-to-noise ratio (TSNR)}

It is obvious that the SNR is greater in the 3T MRI system than in the $1.5 \mathrm{~T}$, since SNR is theoretically proportional to magnetic field strength. ${ }^{24)}$ However, in the temporal aspect, it actually decreases by system fluctuation, physiological noise ${ }^{21)}$ and apparent image shift due to the B0 shift. ${ }^{12,14)}$ Thus, we used the TSNR ${ }^{25)}$ to estimate the pixel signal fluctuation. The TSNR of each pixel was calculated every $10 \mathrm{~min}$. TSNR was defined as:

$$
\operatorname{TSNR}_{(x, y)}=\frac{\mu_{(x, y)}}{\sigma_{(x, y)}}=\frac{\mu_{(x, y)}}{\sqrt{\frac{1}{N} \sum_{i=1}^{N}\left(s_{(x, y, i)}-\mu_{(x, y)}\right)^{2}}}
$$

where $\mu_{(x, y)}$ is temporal mean of the pixel time series at coordinates $(x, y), \sigma_{(x, y)}$ is the standard deviation of this and $S_{(x, y, i)}$ is a pixel value at coordinates $(x, y)$ on $i$ th acquisition.

\section{1-5 Trend}

If the signal fluctuation shows the same tendencies over all pixels through the plane, adjustments may be quite simple. To evaluate the low frequency trend at each pixel, we calculated the correlation between the pixel time series and monotonically increasing function as $Y(i)=x_{i}\left(x_{1}=1, x_{2}=2, \cdots, x_{n}=N\right)$.

The TC was defined as:

$$
T C_{(x, y)}=\frac{\sum_{i=1}^{N} S_{(x, y, i)} Y_{(i)}-N \mu_{(x, y)} \bar{Y}}{\sqrt{\left[\sum_{i=1}^{N}\left(S_{(x, y, i)}-\mu_{(x, y)}\right)^{2}\right]\left[\sum_{i=1}^{N}\left(Y_{(i)}-\bar{Y}\right)^{2}\right]}} \cdots(5)
$$

where $S_{(x, y, i)}$ is a pixel value at coordinates $(x, y)$ on $i$ th acquisition, $\mu_{(x, y)}$ is the temporal mean of a pixel at coordinates $(x, y)$, and $\bar{Y}$ is a mean value of monotonically increasing function. Note that TC was calculated every $10 \mathrm{~min}$. 
Table 2 B0 fluctuation and image shift to the phase direction ( $Y$-axis) during system load

\begin{tabular}{|c|c|c|c|c|}
\hline \multicolumn{5}{|c|}{$1.5 \mathrm{~T}$} \\
\hline data \# & $\Delta \mathrm{f}(\mathrm{Hz})$ & ppm & Image shift (pixel) & Scan duration ( $\min$ ) \\
\hline 1 & +41 & +0.64 & 1.60 & 25 \\
\hline 2 & +35 & +0.55 & 1.30 & 20 \\
\hline 3 & +18 & +0.28 & 0.65 & 20 \\
\hline 4 & +25 & +0.39 & 0.96 & 21 \\
\hline 5 & +39 & +0.61 & 1.39 & 23 \\
\hline 6 & +27 & +0.42 & 1.00 & 22 \\
\hline 7 & +33 & +0.52 & 1.31 & 23 \\
\hline 8 & +14 & +0.22 & 0.50 & 23 \\
\hline 9 & +12 & +0.19 & 0.48 & 24 \\
\hline 10 & +20 & +0.31 & 0.73 & 25 \\
\hline 11 & +23 & +0.36 & 0.83 & 25 \\
\hline Average & +26 & +0.41 & 0.98 & 23 \\
\hline \multicolumn{5}{|c|}{$3 \mathrm{~T}$} \\
\hline data \# & $\Delta \mathrm{f}(\mathrm{Hz})$ & ppm & Image shift (pixel) & Scan duration (min) \\
\hline 1 & +40 & +0.32 & 0.023 & 30 \\
\hline 2 & +36 & +0.29 & - & 30 \\
\hline 3 & +41 & +0.33 & 0.014 & 30 \\
\hline 4 & +43 & +0.35 & 0.002 & 30 \\
\hline Average & +40 & +0.32 & 0.013 & 30 \\
\hline
\end{tabular}

\section{Result}

\section{2-1 B0 change and image shift}

The B0 change during system load and image shift along the phase direction are summarized in Table 2. The increase in central frequency is about $1 \mathrm{~Hz} / \mathrm{min}$, and the image shift was about 1 pixel, which was roughly in accordance with the theory $(23.15 \mathrm{~Hz} /$ pixel $)$. Likewise, the central frequency of the $3 \mathrm{~T}$ system increased approximately $40 \mathrm{~Hz} / 30 \mathrm{~min}$ (i.e. $1.3 \mathrm{~Hz} /$ $\min )$. This is equivalent to more than 1 pixel displacement along the phase direction, however, the actual image shift we observed was 0.013 pixel, which was less than $1 / 80$ of the theoretical value compared to the theoretical image shift.

Fig. 1 shows the realignment parameters $(a, b$ : phantom; c, d: volunteer; a, c: CP-coil; and b, d: $12 \mathrm{ch}$-coil) in the $3 \mathrm{~T}$ data. The letters $\mathrm{X}, \mathrm{Y}, \mathrm{Z}$ in this figure denote the direction of frequency, phase, and slice, respectively. Note that both image shift patterns of a vs. $\mathrm{b}$ and $\mathrm{c}$ vs. $\mathrm{d}$ were similar and therefore independent of the head coil type.

In the phantom's data (Fig. 1a, b), we did not observe a significant image shift in the Y-direction, which should be obvious in theory. Instead, we observed large image shifts along the $\mathrm{X}$-direction (CP-coil: $0.07 \mathrm{~mm}=0.023$ pixels; $12 \mathrm{ch}$-coil: $0.1 \mathrm{~mm}=$ 0.033 pixels) and Z-direction (CP-coil: $0.14 \mathrm{~mm}$; $12 \mathrm{ch}$-coil: $0.18 \mathrm{~mm})$.

\section{2-2 PSC}

Fig. 2 shows the time course of PSC of all slices, and the typical time course from the middle slice is also shown in the small graph in Fig. 2. Signal fluctuations in the $3 \mathrm{~T}$ system were relatively stable, and it was actually $1 / 2-1 / 3$ of the minimum to maximum width of the $1.5 \mathrm{~T}$ system. The ranges of these fluctuations were $\pm 0.5 \%$ in the phantom and $\pm 2 \%$ in the volunteer. Moreover, we observed an increased variance in the data from the volunteers in the $3 \mathrm{~T}$ system as the number of scans grew. When we compared the noise variance between the first and later half of the de-trended time series (e.g. the time course of the middle slice as shown in the small graph in Fig. 2), it was found that noise variance increased by three times or more in the later part.

\section{2-3 ACF and CCF}

Fig. 3 shows the ACF and CCF, where the horizon- 


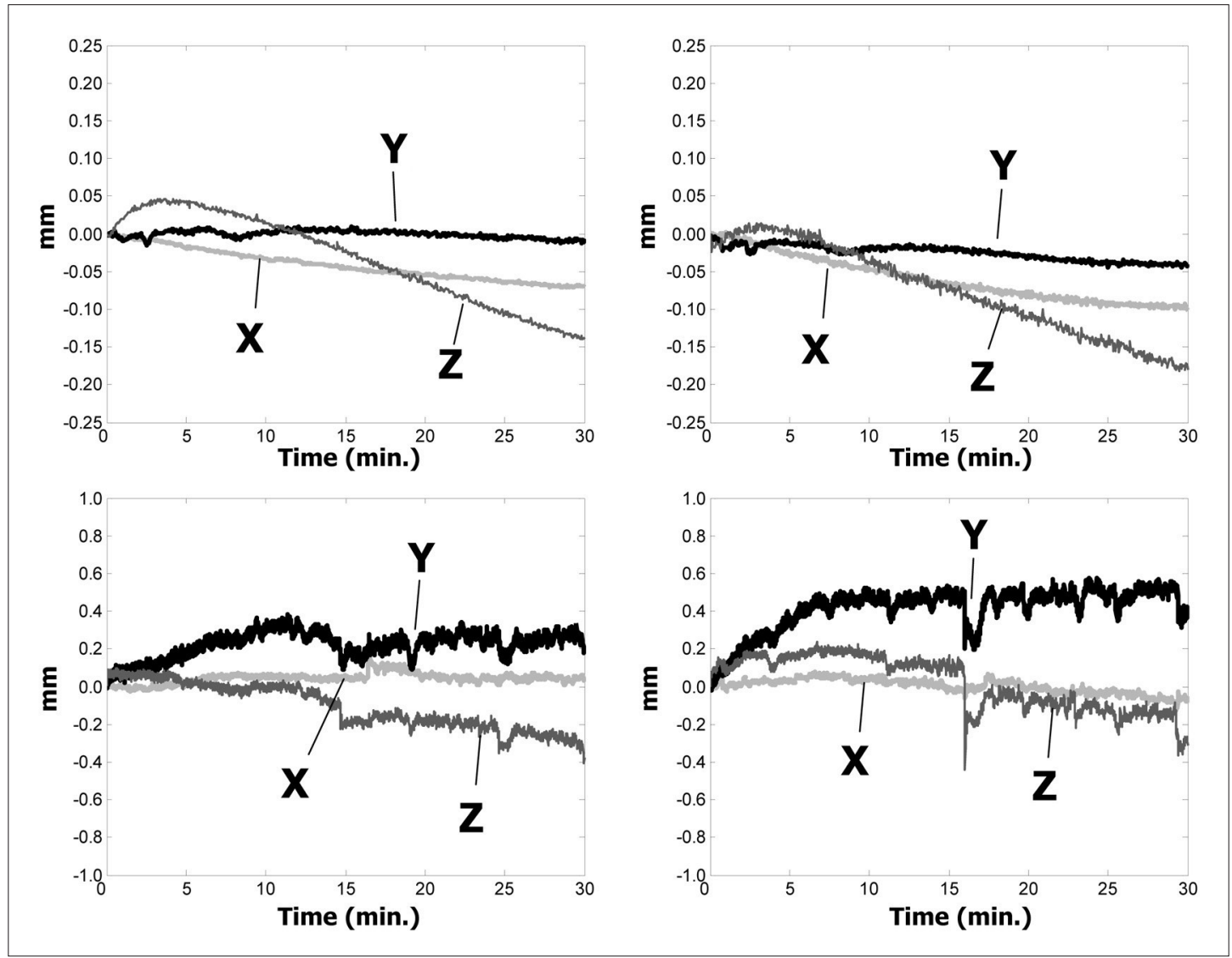

Fig. 1 The realignment parameters (a, b: phantom; c, d: volunteer, a, c: CP-coil; and $\mathrm{b}, \mathrm{d}$ : 12ch-coil) in the 3T data.

The letters $\mathrm{X}, \mathrm{Y}, \mathrm{Z}$ in the figure denote the direction of frequency, phase, and slice, respectively.

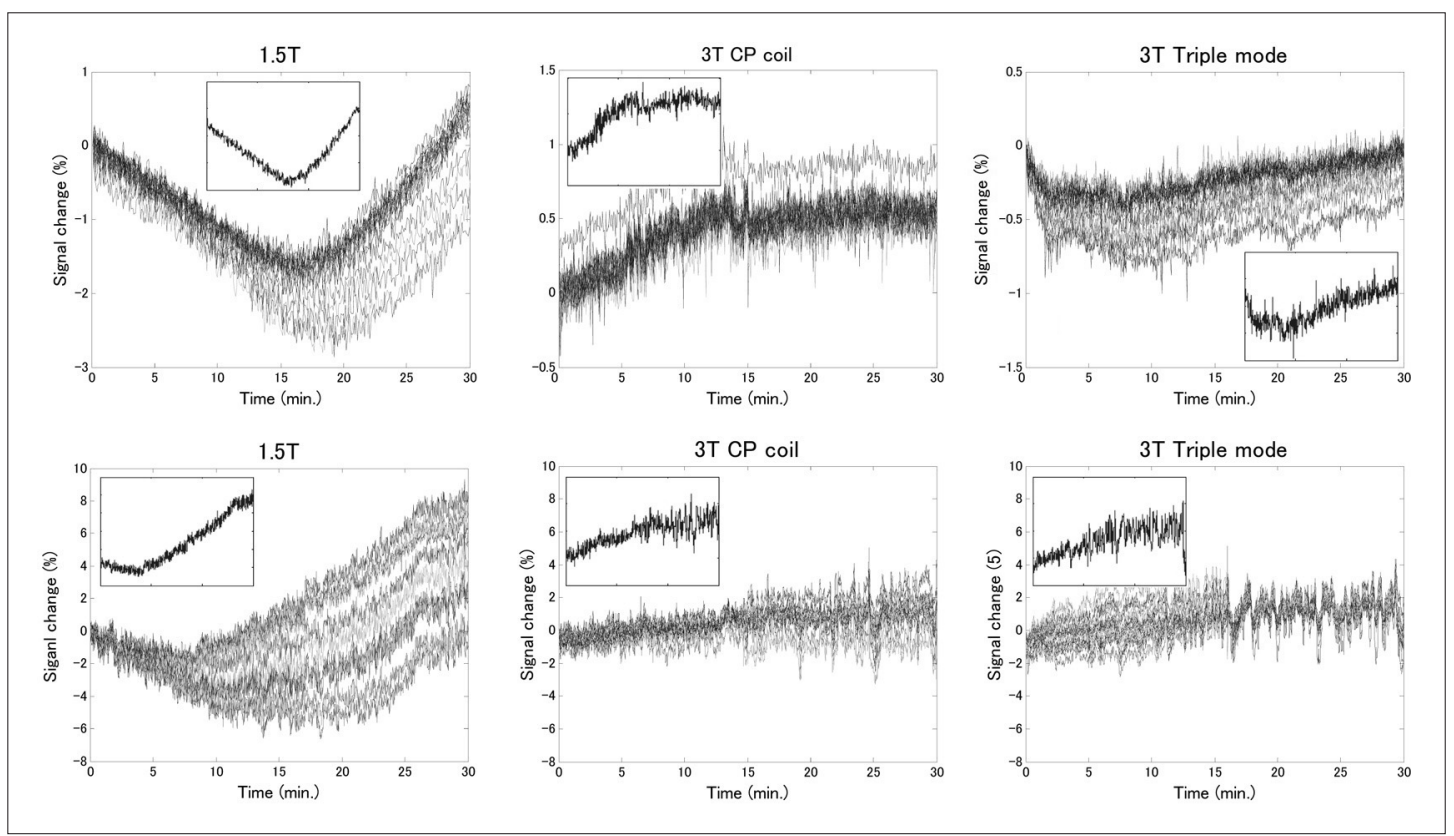

Fig. 2 Time course of PSC of all slices.

Typical time series of the PSC was shown in the small graph. The upper row $(a, b, c)$ shows phantom data and the bottom row (d, e, f) shows volunteer data. Left column ( $a, d)$, middle column (b, e), and right column (c, f) show 1.5T, 3T using CP-coil and 3T using 12ch-coil, respectively.

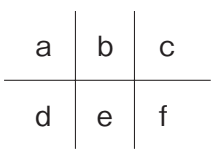


tal axis represents the lag (or sec, in this case) and the vertical axis represents the ACF and/or CCF. Periodical fluctuation of the cycle of 30-40 sec, which is indicated by small triangles in the graph, was observed. This periodical fluctuation was also observed in the other volunteer's data (Fig. 3c, gray line), and more importantly, the period of fluctuation was similar between different volunteers (B and C) as shown in CCF (Fig. $3 c$, black line).

\section{2-4 TSNR}

Fig. 4 shows TSNR images of every $10 \mathrm{~min}$ in sequence. The pixel TSNRs in the $3 \mathrm{~T}$ system (Fig. 4b, c, e, f) were approximately 1.7-2.0 times greater at the CP-coil (i.e. Fig. 4 a vs. b and d vs. e) and approximately 2.5-4.0 times greater at the $12 \mathrm{ch}$-coil (i.e. Fig. 4 a vs. c and d vs. f) than that of the $1.5 \mathrm{~T}$ system (Fig. 4a, b). A torus-shaped higher SNR region was observed in the 12ch-coil when we used the phantom (Fig. 4c; see first $10 \mathrm{~min}$ and last $10 \mathrm{~min}$ of TSNR images).

\section{$2-5$ TC}

Fig. 5 shows the signal trend of pixel time series of every $10 \mathrm{~min}$ in sequence. The lower graph shows the PSC of the center slice as presented in Fig. 2. Distinctive spatial non-uniformities of signal trend were observed on the 3T data (Fig. 5b, c, e, f) .

\section{Discussion}

The B0 fluctuation of MRI during the system load has often been reported, ${ }^{11-15)}$ and this causes image shifts, where the degree of shift and direction depend on the imaging sequence. In the EPI sequence, the B0 change can affect the image position in both phase and frequency directions simultaneously. In this study, the image shift along the phase direction ( $\mathrm{Y}$-axis) is expected to be 64 times greater than the frequency direction (X-axis) in theory. ${ }^{26)}$ However, the image shift along the phase direction was quite small, but that along the frequency direction remained in the theoretical level as shown in Fig. 1a, b (i.e. phantom data). Therefore, we suppose that the phase shift correction during the image reconstruction may be applied and actually functioned well.

Fig. 2 suggested that the PSC and the TSNR of the $3 \mathrm{~T}$ system were stable compared to that of the $1.5 \mathrm{~T}$. In the volunteer's PSC by the 3T system, however, the variance progressively increased in the latter half of the
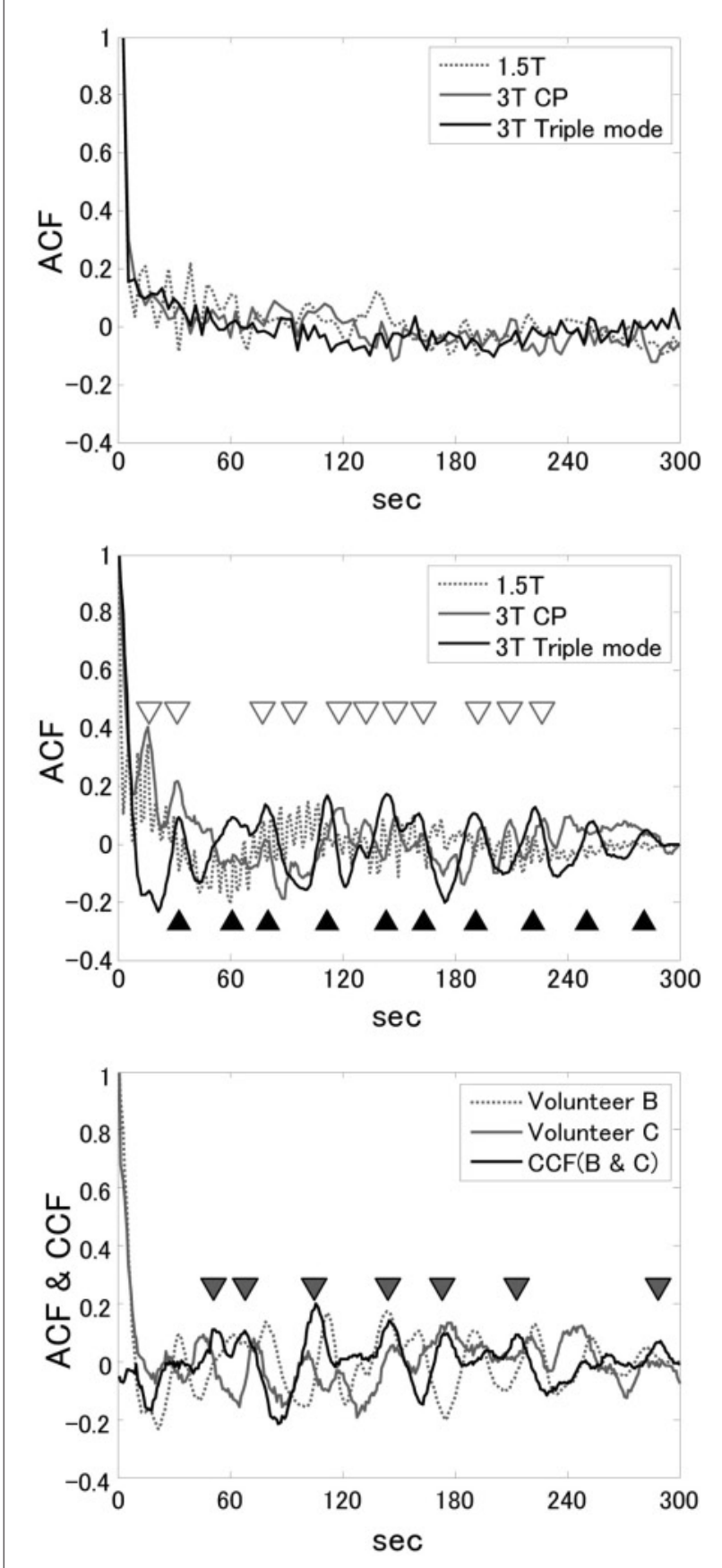

Fig. 3 The top (a) and middle (b) figures show the ACF by phantom and volunteer, respectively. Bottom (c) shows the ACF by volunteers $B, C$ and the CCF between volunteers $B$ and $C$.

The horizontal axis represents the lag (or sec) and the vertical axis represents the ACF and/or CCF. Triangles in Fig. 3c indicate the peak of periodical fluctuation.

time course (see small graph in Fig. 2e, f). This change was specific to the volunteer's data by the 3T. According to the references, ${ }^{27-30)}$ body temperature increased by the heating effect of radio-frequency ( $R F)$ pulse ${ }^{27-29)}$ and become higher over time. ${ }^{29)}$ Moreover, the relationship between cerebral blood flow (CBF) and artificial 


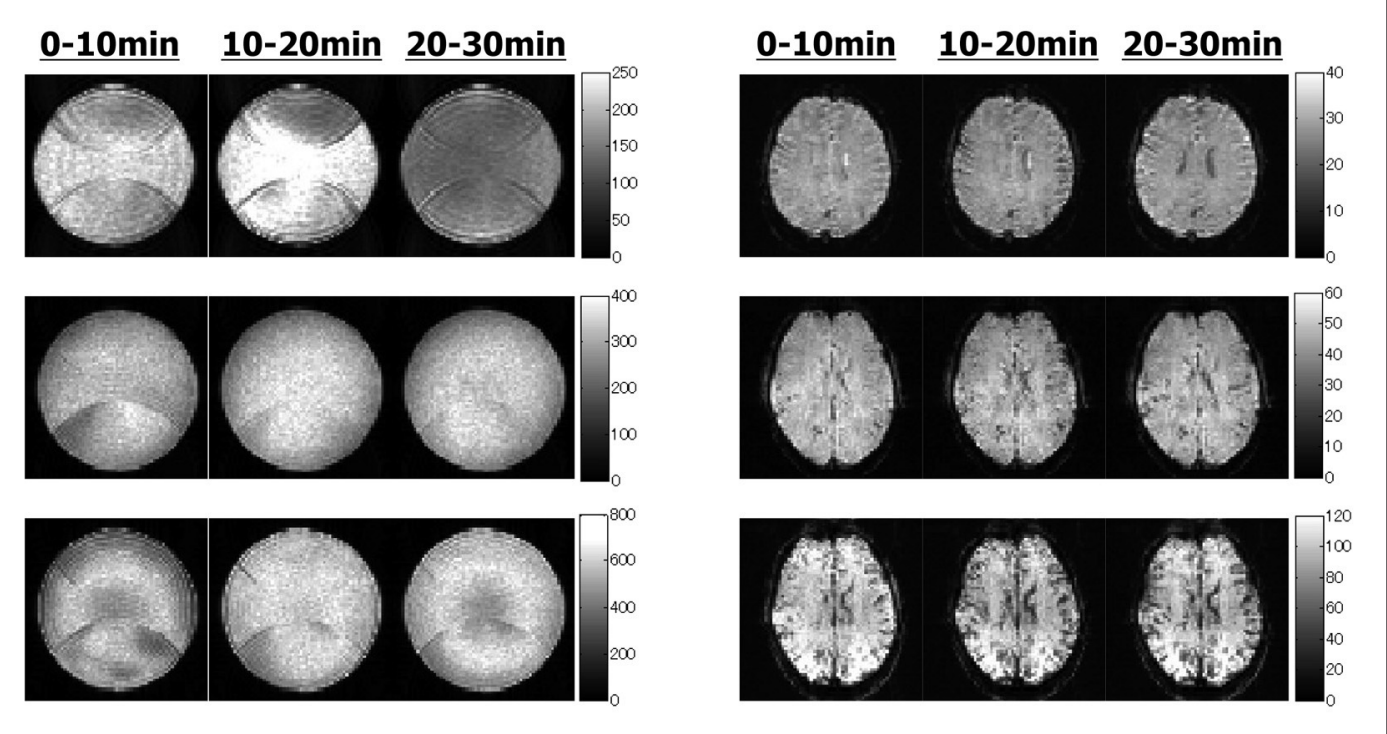

Fig. 4 TSNR images of every $10 \mathrm{~min}$ in sequence.

The top row $(\mathrm{a}, \mathrm{d})$ is $1.5 \mathrm{~T}$ data. The middle $(\mathrm{b}, \mathrm{e})$ and bottom rows $(\mathrm{c}, \mathrm{f})$ are 3T data by CP-coil and 12ch-coil, respectively.
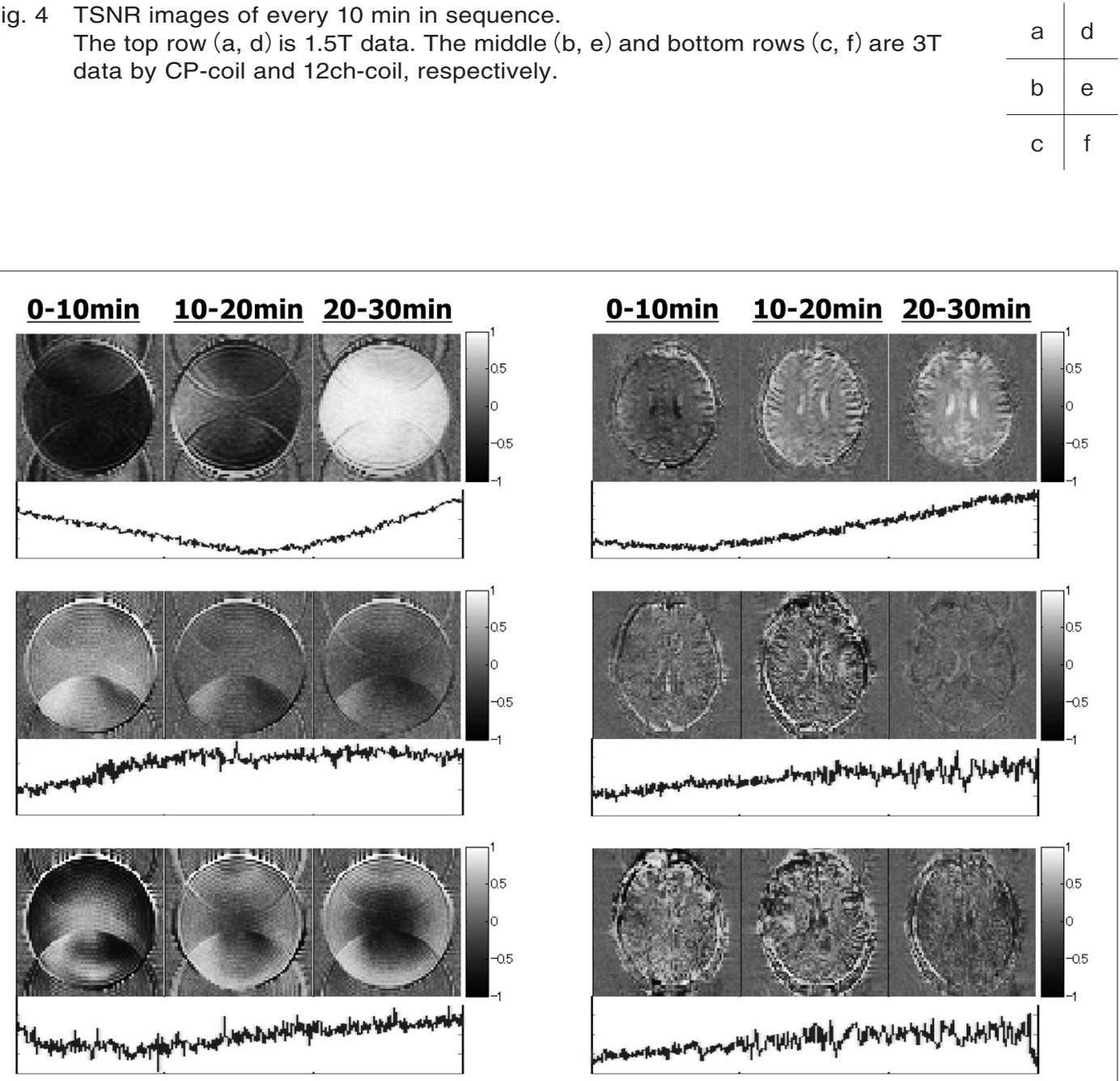

Fig. 5 The linear trends of signal fluctuations (i.e. TC) of every $10 \mathrm{~min}$ in sequence. The lower graph shows the PSC time course of the middle slice as presented in Fig. 2. The middle (b, e) and bottom rows (c, f) are 3T data by CP-coil and 12 ch-coil, respectively. The TC ranges from -1.0 (black) to 1.0 (white). The value represents the degrees of correlation with the monotonically increasing function.

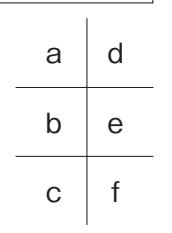


elevation of brain temperature are liner $(10 \%$ per $\left.1^{\circ} \mathrm{C}\right) .^{30)}$ Hence, the variance fluctuation we observed might be attributed to heat accumulation from continuous exposure to RF pulse and/or increased CBF, and we would emphasize careful attention to volunteers during prolonged scans or experiments with the 3T.

We observed the periodical fluctuation with a cycle of about 30-40 sec in ACF (Fig. 3) at the 3T. This may cause a serious problem in the f-MRI experiment because the periodic fluctuation we observed could synchronize with the experimental paradigm, which has a cycle of 40-60 sec as usual. Since it was commonly observed among different volunteers as shown in the CCF and, furthermore, the period was too long to believe that this phenomenon was of physiological origin, we speculate that it might be attributed to some sort of system fluctuation with our $3 \mathrm{~T}$ system. However, we unexpectedly could not observe such a fluctuation in the phantom and suppose that this may result from the phantom characteristics, such as high fluidity of the liquid phantom. Further study will need to clarify the origin of this phenomenon, and the design of the new phantom whose fluidity can simulate biological tissues is required.

We also observed spatial non-uniformity in the TSNR (Fig. 4) and TC (Fig. 5) of the phantom data at 3T. This is also a serious problem because this may cause positional bias in the f-MRI data analysis. Therefore, we have to conduct further investigations to confirm whether this phenomenon is specific to the phantom or not by using a special liquid phantom with controlled fluidity and persistence.

Finally, we would emphasize that our observations in this study were not the general features of the 3T MRI system. It is quite natural that image qualities and characteristics are different across B0 strength, system set-ups ${ }^{19,20)}$ and even MRI manufacturers. Therefore, it is important for each MRI center to know its own system characteristics and incorporate them, for example, in creating experimental design and conducting analysis. In particular, it is important to carefully evaluate the image time series in term of temporal stabilities after system installation. We believe that the measurement method we used in this study, for example, image shift and signal fluctuation are useful. Besides work at the center level, we report that multi-center and/or multi-scanner comparative studies $\left.{ }^{19}, 20,31\right)$ have already begun in the United States to standardize the MRI system. Such an attempt will also be needed in Japan.

\section{Conclusion}

We evaluated the spatio-temporal characteristics of MRI systems (1.5T and 3T) installed at ATR-BAIC by using relatively long duration EPI (up to $30 \mathrm{~min}$ ). As a result, we confirmed that the PSC and the TSNR in the $3 \mathrm{~T}$ were excellent compared to the $1.5 \mathrm{~T}$ and that the $3 \mathrm{~T}$ system was applicable to similar f-MRI experiments that have been performed with the 1.5T. On the other hand, we found some problems, including low frequency periodic fluctuations in the volunteers but not in the phantom, time-dependent increase of noise variance, positional dependence of signal trends, and TSNR. These results should be incorporated in experimental design and analysis.

\section{References}

1) Warnking JM, Pike GB. Bandwidth-modulated adiabatic RF pulses for uniform selective saturation and inversion. Magn Reson Med 2004; 52 (5) : 1190-1199.

2) Ulloa JL, Guarini M, Guesalaga A, et al. Chebyshev series for designing RF pulses employing an optimal control approach. IEEE Trans Med Imaging 2004; 23 (11): 1445-1452.

3) Fujita H. New horizons in MR technology: RF coil designs and trends. Magn Reson Med Sci 2007; 6(1) : 29-42.

4) Wiggins GC, Potthast A, Triantafyllou C, et al. A 96-channel MRI system with 23- and 90-channel phase array head coils at 1.5 Tesla. Proc Intl Soc Mag Reson Med 2005; 13: 671.

5) Mekle R, Gruetter R. Comparison of a TEM head coil with an 8 channel head array coil at 3 Tesla. Proc Intl Soc Mag Reson Med 2006; 14: 3557.
6) Nael K, Fenchel M, Krishnam M, et al. High-spatialresolution whole-body MR angiography with highacceleration parallel acquisition and 32-channel 3.0-T unit: initial experience. Radiology 2007; 242(3) : 865-872.

7) Stoeckel B, Potthast A, Oesingmann N, et al. An MRI system with 128 seamlessly integrated receive channels for multi-nuclear operation. Proc Intl Soc Mag Reson Med 2008; 16: 1119.

8) Jezzard P, Song AW. Technical foundations and pitfalls of clinical fMRI. Neuroimage 1996; 4(3 Pt 3) : S63-S75.

9) Birn RM, Bandettini PA, Cox RW, et al. Magnetic field changes in the human brain due to swallowing or speaking. Magn Reson Med 1998; 40(1) : 55-60.

10) Van de Moortele PF, Pfeuffer J, Glover GH, et al. Respiration-induced B0 fluctuations and their spatial distribution in the human brain at 7 Tesla. Magn Reson 
Med 2002; 47 (5) : 888-895.

11) Kochunov PV, Liu HL, Andrews T, et al. A B (0) shift correction method based on edge RMS reduction for EPI fMRI. J Magn Reson Imaging 2000; 12 (6) : 956-959.

12) Liu HL, Kochunov P, Lancaster JL, et al. Comparison of navigator echo and centroid corrections of image displacement induced by static magnetic field drift on echo planar functional MRI. J Magn Reson Imaging 2001; 13(2) : 308-312.

13) Sutton BP, Noll DC, Fessler JA. Dynamic field map estimation using a spiral-in/spiral-out acquisition. Magn Reson Med 2004; 51(6): 1194-1204.

14) Foerster BU, Tomasi D, Caparelli EC. Magnetic field shift due to mechanical vibration in functional magnetic resonance imaging. Magn Reson Med 2005; 54(5): 1261-1267.

15) Benner T, van der kouwe AJ, Kirsch JE, et al. Real-time RF pulse adjustment for B0 drift correction. Magn Reson Med 2006; 56(1): 204-209.

16) Haruno M, Kuroda T, Doya K, et al. A neural correlate of reward-based behavioral learning in caudate nucleus: a functional magnetic resonance imaging study of a stochastic decision task. J Neurosci 2004; 24(7): 1660-1665.

17) Shimada Y, Fujimoto I, Callan A, et al. Cause of low frequency drift in time series EPI signal. Proc. 59th JSRT 2003: 274 (author's transl., in Japanese).

18) Shimada Y, Fujimoto I, Syakudo Y, et al. Improvement approach for time series EPI. Proc. 61st JSRT 2005: 217 (author's transl., in Japanese).

19) Friedman L, Glover GH, Krenz D, et al. Reducing interscanner variability of activation in a multicenter fMRI study: role of smoothness equalization. Neuroimage 2006; 32(4) : 1656-1668.

20) Friedman L, Glover GH, The FBIRN Consortium. Reducing interscanner variability of activation in a multicenter fMRI study: controlling for signal-to-fluctuation-noiseratio (SFNR) differences. Neuroimage 2006; 33 (2): 471-481.

21) Krüger G, Kastrup A, Glover GH. Neuroimaging at $1.5 \mathrm{~T}$ and 3.0 T: comparison of oxygenation-sensitive magnetic resonance imaging. Magn Reson Med 2001; 45(4): 595-604.

22) Schmitz BL, Aschoff AJ, Hoffmann MH, et al. Advantages and pitfalls in $3 \mathrm{~T}$ MR brain imaging: a pictorial review. AJNR Am J Neuroradiol 2005; 26(9) : 2229-2237.

23) Voss HU, Zevin JD, McCandliss BD. Functional MR imaging at $3.0 \mathrm{~T}$ versus $1.5 \mathrm{~T}$ : a practical review. Neuroimaging Clin N Am 2006; 16(2) : 285-297.

24) Edelstein WA, Glover GH, Hardy CJ, et al. The intrinsic signal-to-noise ratio in NMR imaging. Magn Reson Med 1986; 3(4) : 604-618.

25) Bodurka J, Ye F, Petridou N, et al. Mapping the MRI voxel volume in which thermal noise matches physiological noise-implications for fMRI. Neuroimage 2007; 34 (2) : 542-549.

26) Zhao Y, Anderson AW, Gore JC. Computer simulation studies of the effects of dynamic shimming on susceptibility artifacts in EPI at high field. J Magn Reson 2005; 173(1): 10-22.

27) Shellock FG. Radiofrequency energy-induced heating during MR procedures: a review. J Magn Reson Imaging 2000; $12(1): 30-36$

28) Collins CM, Liu W, Wang J, et al. Temperature and SAR calculations for a human head within volume and surface coils at 64 and 300 MHz. J Magn Reson Imaging 2004; 19 (5) : 650-656.

29) Akca IB, Ferhanoglu O, Yeung CJ, et al. Measuring local RF heating in MRI: simulating perfusion in a perfusionless phantom. J Magn Reson Imaging 2007; 26(5): 1228-1235.

30) Moriyama E. Cerebral blood flow changes during localized hyperthermia. Neurol Med Chir (Tokyo) 1990; 30 (12) : 923-929.

31) Zou KH, Greve DN, Wang M, et al. Reproducibility of functional MR imaging: preliminary results of prospective multi-institutional study performed by biomedical informatics research network. Radiology 2005; 237 (3): 781-789.

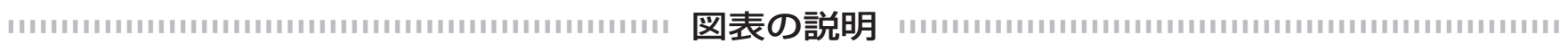

Fig. 1 3Tにおけるrealignment parameter (a, bはphantom, c, dは被験者, a, cはCP-coil, b, dは12ch-coilである).

図中のX，Y，Zはそれぞれ周波数，位相，スライス方向を示す.

Fig. 2 各スライス平均信号のPSCを示す.

代表的なPSCを小グラフに示した。 上段の三つ ( a , b , c ) はphantomデータ, 下段の三つ $(\mathrm{d}, \mathrm{e}, \mathrm{f})$ は被験者データである. 左列 (a, d) は1.5Tのデー夕, 中央列 (b, e)はCP-coilを用いた3Tデー夕, 右列 (c, f) は12ch-coilを用いた 3Tデータである.

Fig. 3 上段 $(\mathrm{a})$ と中央 $(\mathrm{b})$ はそれぞれphantomと被験者のACFである.下段(c)には被験者B，Cの各ACF抢よびこの両被験者間 データに扔けるCCFを示した.

横軸はラグ $(\mathrm{sec})$, 縦軸は $\mathrm{ACF}, \mathrm{CCF}$ 示す。周期性変動のピークを図中に $\triangle$ 印で示した.

Fig. 4 1.5T (a, b) と 3T (b, c, e, f) データの各10分ごとのTSNR画像を順に示す.

Fig. 5 1.5T (a, b)と 3T (b, c, e, f $)$ データの各10分ごとのTC画像を順に示す.

図下グラフはFig. 2 でも示した代表的なスライス信号変動のグラフである. TCの表示幅は-1.0(黒)から1.0(白)となる。マ ナスは単純増加関数に対して逆方向に信号が変動していることを示し，プラスは順方向を示す.

Table 1 撮像パラメータ

Table 2 システム稼働中のB0変動量と位相方向への画像シフト 